\title{
The step project: societal and political engagement of young people in environmental issues
}

Maria Vogiatzi

Christodoulos Keratidis

Manos Schinas

Sotiris Diplaris

Serdar Yümlü

Paula Forbes

Symeon Papadopoulos

Panagiota Syropoulou

Lazaros Apostolidis

loannis Kompatsiaris

Machi Symeonidou

This is the Author Accepted version of this conference paper.

The finai pubiication is availabie at Springer via http://dx.doi.org/10.1007/978-3-319-70284-1_12 


\title{
The STEP project: Societal and political engagement of young people in environmental issues
}

\author{
Maria Vogiatzi ${ }^{1}$, Christodoulos Keratidis ${ }^{1}$, Manos Schinas ${ }^{2}$, Sotiris Diplaris ${ }^{2}$, Serdar \\ Yüml ̈̈ ${ }^{3}$, Paula Forbes ${ }^{4}$, Symeon Papadopoulos ${ }^{2}$, Panagiota Syropoulou ${ }^{1}$, Lazaros \\ Apostolidis $^{2}$, Ioannis Kompatsiaris ${ }^{2}$ and Machi Symeonidou ${ }^{1}$ \\ ${ }^{1}$ DRAXIS Environmental SA, Mitropoleos 63, 54623 Thessaloniki, Greece \\ ${ }^{2}$ Information Technologies Institute, Centre for Research and Technology Hellas, $6{ }^{\text {th }} \mathrm{Km}$. \\ Charilaou-Thermi road, 57001Thermi, Thessaloniki, Greece \\ ${ }^{3}$ Sampas Bilisim Ve Iletisim Sistemleri Sanayi Ve Ticaret A.S., Çubuklu Mahallesi Orhan Veli \\ Kanık Caddesi Eryılmaz 34810, Istanbul, Turkey \\ ${ }^{4}$ Abertay University, Bell Street, Dundee, Scotland \\ mvogiatzi@draxis.gr
}

\begin{abstract}
Decisions on environmental topics taken today are going to have long-term consequences that will affect future generations. Young people will have to live with the consequences of these decisions and undertake special responsibilities. Moreover, as tomorrow's decision makers, they themselves should learn how to negotiate and debate issues before final decisions are made. Therefore, any participation they can have in environmental decision making processes will prove essential in developing a sustainable future for the community.

However, recent data indicate that the young distance themselves from community affairs, mainly because the procedures involved are 'wooden', politicians' discourse alienates the young and the whole experience is too formalized to them. Authorities are aware of this fact and try to establish communication channels to ensure transparency and use a language that speaks to new generations of citizens. This is where STEP project comes in.

STEP (www.step4youth.eu) is a digital Platform (web/mobile) enabling youth Societal and Political e-Participation in decision-making procedures concerning environmental issues. STEP is enhanced with web/social media mining, gamification, machine translation, and visualisation features.

Six pilots in real contexts are being organised for the deployment of the STEP solution in 4 European Countries: Italy, Spain, Greece, and Turkey. Pilots are implemented with the direct participation of one regional authority, four municipalities, and one association of municipalities, and include decision-making procedures on significant environmental questions.
\end{abstract}

Keywords: e-participation, social media mining, environmental decision making, youth engagement strategies 


\section{E-participation}

Promoting youth participation is fundamental in the EU policy. It is an underlying theme of the EU Youth Strategy, and it is incorporated into the Treaty of Lisbon, where Article 165 TFEU stipulates that 'Union action shall be aimed at encouraging the participation of young people in democratic life in Europe'.

According to the findings of the Eurobarometer (Standard EB 77, spring 2012), half of the young people tend to distrust the European Union. Traditional channels of representative democracy, such as voting at elections and joining political parties only partially stimulate young people's interest in active participation. The percentage of young people voting in elections and being members of a political party is significantly lower than that of their elders. [1]

As a reaction to this public discontent, many European countries have started exploring the potential of Information and Communication Technology (ICT) to regain citizens' trust and revitalise European democracy by developing a more responsive, transparent, and participatory decision-making process. [2]

The participation of young people in decision making is especially relevant and extremely important in environmental issues. Decisions taken now on matters such as climate change, the depletion of resources, and the loss of biodiversity will have longterm consequences that will affect the future generations. Young people will have to live longer with the consequences of current decisions, and have special concerns and responsibilities in relation to the environment. Their participation in environmental decision making is an essential part of developing a sustainable future.

\section{STEP project}

The STEP project (www.step4youth.eu) is supported by the European Union's Horizon 2020 research and innovation programme and aims to increase and support participation of young European citizens in decision making for environmental issues. STEP will develop and pilot test a cloud eParticipation platform that will facilitate interaction between policy makers and young people and will enable youth Societal and Political e-Participation in decision-making procedures concerning environmental issues. The main goal of the STEP project is to directly involve at least 8,000 participants in the respective environmental pilots and indirectly inform more than 80,000 people on e-participation.

The STEP Platform (www.step.green) is enhanced with a number of features, so as to become appealing to young people and engage them in e-participation processes. The platform was launched to the general public on February 2017 and is available as a mobile (both iOS and Android) and web application.

The main ideas underpinning the STEP project and the platform are briefly described below:

- e-participation features: The STEP platform offers a wide range of e-participation features that serve both top-down and bottom-up approaches. 
- Integrated platform: STEP uses social media / web mining technologies that enable young people to view personalized and enriched information relevant to the topic they are viewing, filtered through multiple social media and web sources, in one unified environment.

- Engagement: Social media analytics and monitoring tools can be used by the authorities in order to facilitate the identification of the preferences of young people, and thus develop an effective strategy to engage young citizens.

- Removal of language barriers: Machine translation technology allows users to access content from other countries in their own language, removing language barriers and fostering cross-border interaction.

- Policy-making support: Visual representations of results that enable policy makers to interpret the results of their campaigns, view patterns and spot trends, facilitating decision making.

\section{STEP pilots}

Six pilots in real contexts are being organised for the deployment of the STEP solution in 4 European Countries: Italy, Spain, Greece, and Turkey. Pilots are implemented with the direct participation of one regional authority, four municipalities, and one association of municipalities, and include decision-making procedures on significant environmental questions. During the STEP pilot, the public authorities invite young citizens to use the platform and participate in decision making processes on local environmental issues.

In order to assist the pilot partners for setting up their public participation processes effectively, a framework for public participation has been created, by combining information from available best practice guidelines and toolkits and adapting it to the STEP project specificities. This framework aims to provide a high-level consultation to the pilot authorities when deciding how best to execute the pilot needs in environmental decision-making.

Available best practice guidelines have been identified and reviewed, such as:

- Guidelines for successful e-participation by young people, Best practice manual [3]

- $\quad$ OPIN Guidelines - Draft created by EUth project [4]

- US Environmental Protection Agency Public Participation Guide [5]

- Public Participation in Government Decision-making, Better practice guide of Victorian Auditor-General's Office [6]

- Guidelines for successful e-participation by young people in decision-making at local, regional, national and European levels, International Youth Service of the Federal Republic of Germany [7]

These guidelines structure the public participation process by breaking it down to different phases, and present comprehensive recommendations for each phase in order 
to support the public authorities, or the operators to fully understand the procedures and implement in detail each phase of the public participation. Some of them are specifically related to e-participation of young people, while one focuses on environmental issues.

In addition to the guidelines above, the toolkits for public participation of the US Environmental Protection Agency in cooperation with the International Association for Public Participation (IAP2) and other organisations have been reviewed. These toolkits provide basic information and ideas as well as useful links to more content on the web. They follow a logical path to understand, plan, and implement a public participation process. Additionally, they are designed with government agencies in mind, to help those who must manage processes where public input is important to decisionmaking and provide a clear overview of important considerations in the design and implementation of a public participation initiative such as the STEP project's pilot. The following toolkits have been reviewed:

- Core Values for the Practice of Public Participation, International Association for Public Participation (IAP2) [8]

- Core Principles for Public Engagement, National Coalition for Dialogue \& Deliberation (NCDD) [9]

- Participation and Civic Engagement, World Bank [10]

- Better Decisions through Consultation and Collaboration, US Environmental Protection Agency (EPA) [11]

- Spectrum of Public Participation, International Association for Public Participation (IAP2) [12]

- How to Consult and Involve the Public, US Environmental Protection Agency (EPA) [13]

- How to Evaluate Public Involvement, US Environmental Protection Agency (EPA) [14]

As every public participation procedure is unique, it should be planned based on its particularities. For this reason, the STEP public participation framework has been developed by selecting relevant elements from these guidelines and toolkits.

The STEP public participation includes 5 basic steps:

- STEP 1: Background: This step is about mapping the general context of the pilot, and starts at the beginning of the project.

- STEP 2: Planning: The planning step includes the main preparation activities and sets concrete goals, timeframe, responsibilities, and rules. This is the first step for realizing what has been sketched out in the Background.

- STEP 3: Action: The actual pilot execution of the e-participation process, once the environment is prepared and the whole process planned.

- STEP 4: Communication: This is a key step that includes all the communication activities which will be performed throughout the pilot lifetime. The most important mission of this step is to engage young people and increase STEP popularity. 
- STEP 5: Feedback and evaluation: Feedback is an iterative process as the collected input by the platform users enhances and enriches the evaluation process, while the quality of the evaluation enables continuous improvement and learning through its implementation.

In order to define the local pilot plans in a structured and uniform way, a questionnaire was developed for the collection of information from the pilot partners. The questionnaire includes 10 sections. The questions and recommendations have been formulated by combining elements of the best practice guidelines, which have been selected according to their relevance to the project.

Through the questionnaire the public authorities are guided to define and explain the approach of conducting public participation and how this relates to the particular characteristics of the pilot and meet the needs of decision makers, public authority officers and young citizens. This process results in specifications for the public participation processes, and the input collected will be used to form the local pilot plans.

The questionnaire includes the following sections:

- Objectives and scope: Clear and comprehensive description of the objectives and scope of the participation procedure that the public authority intends to set up.

- Legal framework: Legislation that is relevant to public participation and regulations that the authority has to follow when making a decision.

- Selection of issues to be brought under public participation: Definition of specific issues on which young people will be consulted through the STEP platform.

- Public participation procedure: Definition of the public participation rules, how public participation will be conducted, and how the decision will be made.

- Timeframe: Definition of the steps and the time frame of the process in accordance with the general STEP pilot timeframe.

- Resources and skills: Appointment of a person for each of the following roles: Pilot leader, Platform administrator, Responsible for communication, Responsible for training and Responsible for collecting feedback.

- Communication to stakeholders: Definition of the way in which pilot partners will distribute the information to stakeholders, and how the stakeholders are involved.

- Communication to young citizens: Definition of the strategy and the means to be used in order to engage young citizens.

- Social media management: Definition of the social media to be used and description of usage rules.

- Inclusion: Plans to promote and ensure inclusion of sensitive communities.

The STEP platform was launched to the general public on February 2017 and since then STEP pilots have uploaded a number of questions on local environmental issues. The evaluation of the pilots will take place within the next months and will be concluded on October 2017. 


\section{The technology behind STEP}

The STEP platform is a cloud based SaaS platform that brings together several ideas and technologies with the goal to engage Young European Citizens and Public Authorities in decision making about environmental strategies, policies, plans, programmes, laws, and projects.

The STEP platform is based on a modular service oriented architecture, integrating individual components which are developed/customized so that they can carry out specific business functions, and can be reused, each one individually, by public organizations for quickly opening their decision-making processes. This is especially important for public organizations that already have well set-up procedures for managing participation, and do not want to replace them. Public organizations can however benefit from the use of partial components of STEP, according to their needs, thus integrating them in their regular practice. STEP Platform has the following integrated components: e-Participation, Social media/Web mining and Visualization, Machine Translation and Text-to-Speech. STEP is available on the web at step.green, on Google Play and on App Store in English, Spanish, Italian, Greek, Turkish and Catalan languages.

\section{1 e-Participation}

. The cloud e-Participation component is the central module of the STEP platform, allowing the interaction between end users (policy makers and young people) and the communication with the other platform components. e-Participation supports three types of dialogue management (e-Petition, Consultation, Idea Generation), Mapping, Timeline, Questionnaire, Messaging, Round Table, Embeddable Snippets and leaderboard and badged based Gamification features for public administrations and citizens. The STEP Platform follows the guidelines of Service Oriented Architecture (SOA) for the integration of all platform components and integration with 3rd parties including iOS and Android mobile apps via REST based services. e-Participation component uses Microsoft .Net technologies and applies web and mobile security practices to ensure the confidentiality, integrity and availability of electronic information captured, stored, maintained, and used by the STEP platform. It also provides a common logging service is being developed for as a user interaction log system within the platform.

\subsection{Social media/Web mining and Visualization}

. STEP Platform uses social media and web mining technologies that enable young people to view personalized and enriched information relevant to the topic of their interest. Information is filtered through multiple social media and web sources, such as Facebook, twitter, and so on, and presented in a single unified environment. This tool eliminates the need to search for content on multiple platforms, or navigate through the overflow of information available. Web and social media mining component presents emerging topics from social media and the web relevant to users' inter- 
ests in two different interfaces separately for PAs and citizens. For PAs, visualization of the content is provided via map and timeline based visualisations to help the analysts to identify the spatial distribution of use contributed content, the origin of certain trends and their evolution over time. Social media/Web mining and Visualization uses technologies such as Java, MongoDB, Solr, HTML5, jQuery and REST services for stream management, crawling and API management. Social media mining technologies are further elaborated in section 5 of this paper.

\subsection{Machine Translation (MT) and Text-to-Speech (TTS)}

. STEP Platform uses machine translation technology to allow users to access content from other countries in their own language (English, Spanish, Italian, Greek, Turkish and Catalan), removing language barriers and fostering cross-border interaction. Statistical Machine Translation (SMT) is used in STEP MT that is based on on automatic corpus analysis and statistical learning methods, where both translations and the rules are learned from a sufficient amount of bilingual corpora, i.e. from existing translations. Besides MT, Text to Speech (TTS) technology is used with broad functionalities to allow flexible access from the STEP platform. TTS enables dynamic content provided by users to be read in English, Spanish, Italian, Greek, Turkish and Catalan languages. TTS can convert any text into an WAV and MP3 audio file formats with the following voice parameters support: Speed, Pitch, Volume and Gender.

\section{$5 \quad$ Social media mining}

Social media mining tool is a generic open-source framework for monitoring, analyzing and retrieving content form multiple social media platforms.

Figure 2 depicts the components of the tool, deployed as separate Docker containers. End users of the tool can define collections that represent their information needs through a REST API or by using a usr interface on top of it. These collections can contain a) keywords, 2) accounts or 3) locations. The tool uses that input to collect relevant content and expose analytics over it.

The collection of social media data is performed by the Stream Manager component. Signaling of Stream Manager for collection related events occurred through the API is performed by the Redis publish/subscribe mechanism. Currently, five different platforms are supported: Twitter, Facebook, YouTube, Google+ and Flickr. The Stream Manager collects items shared in these platforms, alongside the users that published them, the embedded multimedia and the linked URLs. The fetched content, after being processed and filtered to improve quality, is stored and indexed in MongoDB and Apache Solr respectively.

Given a user defined collection retrieval of relevant content is performed by using a Solr query. Solr response contains the ids of relevant items, while the actual content is retrieved from MongoDb by id. For analytics, faceting mechanism of Solr is used. More precisely, using the same Solr query as content retrieval facets are calculated 
over several fields such as publication time, user ids, tags etc. These facets correspond to the analytics provided by the tool.

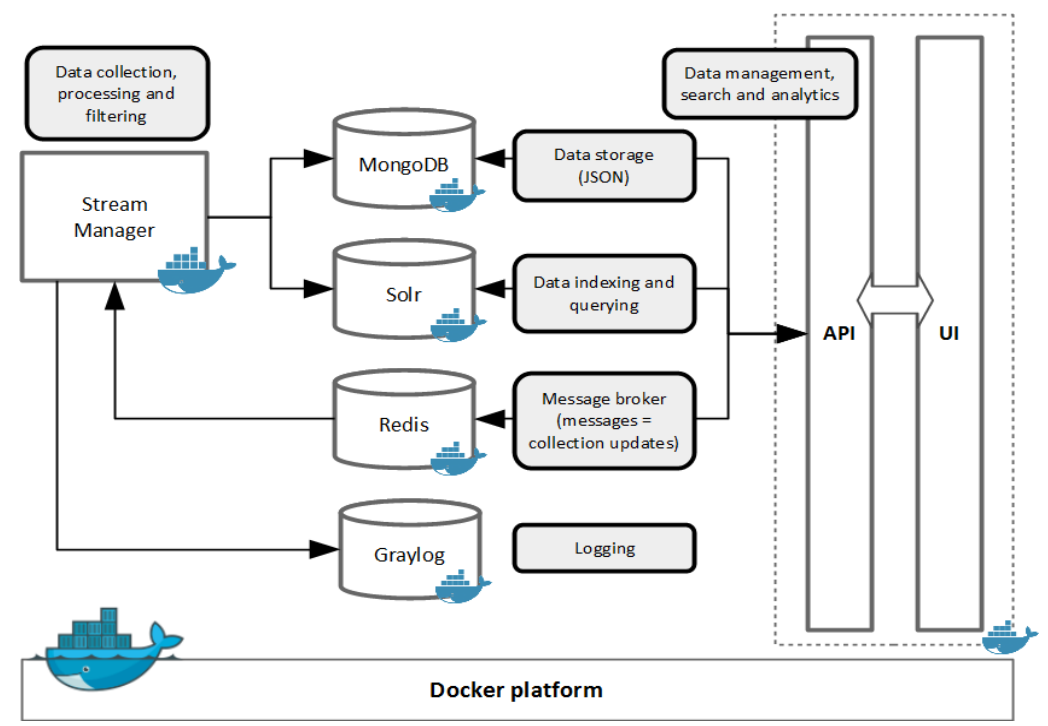

Fig. 1. Overview of social media mining tool and its core components

\section{Conclusions}

This paper presents STEP project, a H2020 project with basic aim to engage even more young people in societal and political participation and to involve them in decision making processes on issues that concern the environment. In this context an interactive platform for e-participation has been developed, which addresses mainly two target groups: young citizens and the representatives of the authorities, who are responsible for decision making. Using the latest advances of technology, the STEP platform has been enriched with a number of features that make the platform friendlier to the user. The STEP platform is currently being pilot tested by 6 authorities in four countries.

\section{References}

"1. Public Opinion In The European Union, Standard Eurobarometer 77 Spring 2012, pp.13, (2012)".

2 "2. Potential and Challenges of E-Participation in the European Union, study commissioned and supervised by the European Parliament's Policy Department for Citizens' Rights and Consti-tutional Affairs at the request of the AFCO Committee, (2016)". 
"e-Participation Best Practice Manual, This manual is the result of Interreg IVC-financed project "eCitizen II - Towards citizen-centered eGovernment in European cities and regions", (2012)".

"EUth project, http://www.euth.net/, last accessed 2017/07/".

"Environmental Protection Agency, Public Participation Guide, https://www.epa.gov/sites/production/files/2014-

05/documents/ppg_english_full-2.pdf, last accessed 2017/07/24".

"Victorian

Auditor-General's

https://www.audit.vic.gov.au/sites/default/files/20150130-Public-

Office, Participation-BPG.pdf, last accessed 2017/07/24".

"International Youth Service of the Federal Republic of Germany "Guidelines for successful e-participation by young people in decisionmaking at local, regional, national and European levels",".

"International Association for Public http://www.iap2.org/?page=a4, last accessed 2017/07/24".

9 "National Coalition for Dialogue \& Deliberation, http://ncdd.org/rc/wpcontent/uploads/2010/08/PEPfinal-expanded.pdf, last accessed 2017/07/25".

10 "World

Bank, http://web.worldbank.org/WBSITE/EXTERNAL/TOPICS/EXTSOCIALDE VELOPMENT/EXTPCENG/0,,contentMDK:20282087 menuPK:1278110 pagePK:148956 piPK:216618 theSitePK:410306,00.html, last accessed 2017/07/24".

11 "Environmental Protection Agency, https://www.epa.gov/internationalcooperation/better-decisions-through-consultation-and-collaboration, last accessed 2017/07/25".

12 "International Association for Public Participation, http://c.ymcdn.com/sites/www.iap2.org/resource/resmgr/foundations_course /IAP2_P2_Spectrum_FINAL.pdf, last accessed 2017/07/24".

13 "Environmental Protection Agency, https://www.epa.gov/internationalcooperation/how-consult-and-involve-public, last accessed 2017/07/24".

"Environmental

Protection https://www.epa.gov/sites/production/files/2015-

Agency, 09/documents/evaluate508.pdf, last accessed 2017/07/24".

15 S. E. 7. S. 2. p. (. 1. Public Opinion In The European Union.

16 "1. Potential and Challenges of E-Participation in the European Union, study commissioned and supervised by the European Parliament's Policy Department for Citizens' Rights and Constitutional Affairs at the request of the AFCO Committee, (2016)". 